\title{
ESR $\alpha$ Promoter Methylation May Modify the Association Between Lipid Metabolism and Type 2 Diabetes in Chinese Farmers
}

\author{
Guoyu Zhou ${ }^{1,2}$, Lihua Liu ${ }^{1}$, Xing Li ${ }^{3}$, Xiangbo Hou ${ }^{1}$, Ling Wang ${ }^{3}$, Renjie Sun ${ }^{1}$, Hui Huang ${ }^{1}$, \\ Zhiyuan $\mathrm{Li}^{1}$, Wenjie $\mathrm{Li}^{3}$, Chongjian Wang ${ }^{4}$ and Yue $\mathrm{Ba}^{1,2 *}$ \\ ${ }^{1}$ Department of Environment Health \& Environment and Health Innovation Team, School of Public Health, Zhengzhou \\ University, Zhengzhou, China, ${ }^{2}$ Yellow River Institute for Ecological Protection \& Regional Coordinated Development, \\ Zhengzhou University, Zhengzhou, China, ${ }^{3}$ Department of Nutrition and Food Health, School of Public Health, Zhengzhou \\ University, Zhengzhou, China, ${ }^{4}$ Department of Epidemiology and Biostatistics, School of Public Health, Zhengzhou University, \\ Zhengzhou, China
}

OPEN ACCESS

Edited by: Daisuke Yabe,

Gifu University, Japan

Reviewed by:

Dongsheng $\mathrm{Hu}$,

Shenzhen University, China

Zhenchao Zhang,

Xinxiang Medical University, China

*Correspondence:

Yue Ba

byyue@zzu.edu.cn

Specialty section:

This article was submitted to

Clinical Diabetes,

a section of the journal

Frontiers in Public Health

Received: 30 June 2020

Accepted: 08 February 2021

Published: 04 March 2021

Citation:

Zhou G, Liu L, Li X, Hou X, Wang L, Sun $R$, Huang $H, L i Z$, Li W, Wang $C$ and Ba Y (2021) ESR $\alpha$ Promoter

Methylation May Modify the

Association Between Lipid Metabolism and Type 2 Diabetes in

Chinese Farmers.

Front. Public Health 9:578134.

doi: 10.3389/fpubh.2021.578134
Objective: This study is aimed to explore the potential association among the estrogen receptor alpha $(E S R \alpha)$ promoter methylation, lipid metabolism and the risk of type 2 diabetes mellitus (T2DM).

Methods: A total of 1143 rural residents were recruited randomly from Henan Province, China. The circulating methylation levels in ESR $\alpha$ promoter region were determined by quantitative methylation-specific polymerase chain reaction. Serum high density lipoprotein cholesterol (HDL-C), low density lipoprotein cholesterol (LDL-C), triglyceride (TG), total cholesterol (TC) and fasting plasma-glucose (FPG) were measured.

Results: The ESR $\alpha$ promoter methylation levels were negatively associated with HDL-C levels whether gender stratification was performed $(P<0.05)$ and positively correlated with LDL-C in men $(P<0.05)$. Each unit standard deviation (SD) increment in TG was associated with a $43 \%$ increase $(95 \% \mathrm{Cl}: 1.25,1.64)$ in the risks of T2DM in all participants, a $36 \%$ increase $(95 \% \mathrm{Cl}: 1.13,1.64)$ in the risks of T2DM in men and a $49 \%$ increase $(95 \% \mathrm{Cl}: 1.21,1.83)$ in the risks of T2DM in women. Furthermore, each SD increment in HDL-C was associated with a reduction of $25 \%(\mathrm{OR}=0.75,95 \%$ Cl: $0.58,0.97)$ in the risks of T2DM in men, and the risk of T2DM in men may be more susceptible to HDL-C than that in women $(P$ for interaction $<0.05)$. Additionally, we found that the risk of T2DM in participants with lower methylation levels $(\leq 4.07 \%)$ were more susceptible to HDL-C ( $P$ for interaction $<0.05)$.

Conclusions: These findings suggested that lipid metabolism was associated with ESR $\alpha$ promoter methylation levels and the risk of T2DM. Besides, the levels of ESR $\alpha$ promoter methylation and gender can modify the association of HDL-C and T2DM.

Keywords: estrogen receptor alpha, DNA methylation, lipid metabolism, diabetes mellitus, farmers 


\section{BACKGROUND}

Type 2 diabetes mellitus (T2DM) poses a worldwide public health problem with a continuously increasing prevalence in both developing and developed countries (1-3). More than half of patients with T2DM suffer from dyslipidemia (4). Diabetic dyslipidemia is mainly a mixed dyslipidemia with higher triglycerides (TG) and low density lipoprotein cholesterol (LDL-C), and lower of high density lipoprotein cholesterol (HDL-C) which can be observed before the onset of diabetes (5-7). The use of lipid-lowing therapy can improve lipid metabolism and prevent T2DM (8). Consequently, exploring the molecular mechanisms underlying abnormal lipid metabolism and T2DM pathogenesis is critical to develop therapeutic strategies for T2DM.

Several evidences indicate that estrogens can regulate lipid metabolism and protect mouse from $\beta$-cell apoptosis $(9,10)$. Estrogens deficiency can contribute to metabolic dysfunction, and then cause obesity and insulin resistance $(11,12)$. Additionally, the estrogens therapy has been revealed to have various beneficial effects by decreasing fasting glucose, increasing insulin sensitivity and secretion and reduce T2DM incidence in postmenopausal women $(13,14)$. Notably, the metabolic effects of estrogens are mediated by estrogen receptor alpha (ESR $\alpha)$ (15). Animal studies revealed that mice were more resistant to insulin after ESR $\alpha$ knockout (11). Furthermore, Ribas et al. (16) found that ESR $\alpha$ deficiency can increase fasting insulin levels, impairs glucose tolerance and results in skeletal muscle insulin resistance. As an important epigenetic modification, DNA methylation is a key regulator of gene expression. Additionally, the methylation of ESR $\alpha$ promoter is reported to reduce the expression of ESR $\alpha$ (17). Furthermore, abnormal DNA methylation were found to be associated with lipid metabolism disorders $(17,18)$. However, whether the alteration of ESR $\alpha$ promoter methylation affects human lipid metabolism and the risk of T2DM has not been explored.

Given these, in this study, we conducted a cross-sectional study in rural areas of Henan Province, and recruited 1,143 Chinese farmers to identify the association of ESR $\alpha$ promoter methylation, lipid metabolism and T2DM. With the development of targeted interventions for DNA methylation (19), this study can provide a theoretical basis for the screening of diabetessusceptible populations and future precision therapy.

\section{METHODS}

\section{Study Participants}

A cross-sectional study was conducted in Wuzhi County of Henan Province in China by random sampling in 2013. Participants were excluded as the following: (1) people with type 1 diabetes; (2) secondary diabetes (drug-induced, chemicalinduced, exocrine pancreatic insufficiency, and genetic defects); (3) gestational diabetes and rare forms of diabetes. Finally, a total

Abbreviations: $E S R \alpha$, estrogen receptor alpha; T2DM, type 2 diabetes mellitus; HDL-C, high density lipoprotein cholesterol; LDL-C, low density lipoprotein cholesterol; TG, triglyceride; TC, total cholesterol; FPG, fasting plasma-glucose. of 1,143 local permanent residents were recruited in this study. The project was approved by the Institutional Review Board at Zhengzhou University. All participants were informed of the purpose of the study and provided written informed consent.

\section{Outcome Variable}

The diagnostic testing for T2DM was performed according to the criteria of World Health Organization (1999) (20) and the guidelines of American Diabetes Association (2002). All the nondiabetic people had normal glucose tolerance after an oral glucose tolerance test (OGTT).

\section{Sampling and Data Collection}

Trained investigators conducted a face-to-face interview with each participant using a standard questionnaire for obtaining information of demographic characteristics including age, gender, economic status, educational level, dietary habits and lifestyle (smoking and drinking, salt intake, physical activity, et, al). Among participants, those who had smoked at least 100 cigarettes in their lifetime were defined as "smoking"; those consuming any drink containing alcohol more than 12 times during the past 12 months were defined as "drinking." A total of $10 \mathrm{~mL}$ fasting blood samples ( $5 \mathrm{ml}$ of anticoagulative and $5 \mathrm{ml}$ of non-anticoagulative) were collected from each participant. Serum samples were isolated from non-anticoagulative blood after centrifugation (3,000 rpm for $15 \mathrm{~min}$ ) at $4^{\circ} \mathrm{C}$ and frozen at $-80^{\circ} \mathrm{C}$ for subsequent analyses.

\section{Measurement of Biochemical Parameters}

The concentration $(\mathrm{mmol} / \mathrm{L})$ of HDL-C, LDL-C, TG, total cholesterol (TC) and FPG in serum samples were measured with direct method of catalase clearance, direct method of surfactant removal, glycerol phosphate oxidase-peroxidase (GPO-PAP), cholesterol oxidase-peroxidase (GHOD-PAP) and glucose oxidative method, respectively (21). Finally, 120 serum samples were randomly selected for repeated measurements. All analyses were run on an automatic biochemical analyzer (Kehua Bio-engineering Co., Ltd, Shanghai, China).

\section{Measurement of ESR $\alpha$ Promoter Methylation}

The genomic DNA was extracted from whole blood samples using a BioTeke Magnetic beads kit (Bioteke Crporation, Beijing, China). The concentration of DNA samples was measured using a Nanodrop ND-2000 spectrophotometer (Thermo, MA, USA). Subsequently, the genomic DNA were treated with sodium bisulfite using an EZ DNA Methylation-Gold kit (Zymo Research, CA, USA). The putative promoter sequences of ESR $\alpha$ the sequence of the gene promoter region assumed to be 2,000 bp upstream from the ESR $\alpha$ start codon (22)] were obtained from UCSC/Ensembl, and then primer sequences (methylated specific primers: L, 5'-CGT AGG TTT ACG GTT AGA TCGG3'; R, 5'-ATA CAA TAA CAT CAA CGA ACT CGAA-3'; unmethylated specific primers: L, $5^{\prime}$-ATG GTT AGA TTG GTT TTT TTT TAGG-3'; R, 5'-ACA TCA ACA AAC TCA AAA ACA CACT- $3^{\prime}$ ) were designed using the methylation primer design software (Methyl Primer Express v1.0). The ESR $\alpha$ 
methylation level was analyzed using quantitative methylationspecific PCR on a MX3000P real-time PCR system (Aglient, Santa Clara, CA, USA). PCR amplification was performed in a $15 \mu \mathrm{l}$ reaction mixture contained $5.5 \mu$ l of diluted DNA template (100 ng), $7.5 \mu \mathrm{l}$ of $2 \times$ Power SYBR Green PCR Master Mixture (CWBIO, Beijing, China), $2 \mu \mathrm{l}$ of primer with a concentration of $1.25 \mu \mathrm{mol} / \mathrm{L}$ each. The PCR cycling parameters were as follows: $95^{\circ} \mathrm{C}$ for $10 \mathrm{~min}$; 40 cycles for degeneration at $94^{\circ} \mathrm{C}$ for $15 \mathrm{~s}$, annealing at $54^{\circ} \mathrm{C}$ for $30 \mathrm{~s}$, and extension at $72^{\circ} \mathrm{C}$ for $30 \mathrm{~s}$. Two negative controls (replace the DNA template with $\mathrm{ddH}_{2} \mathrm{O}$ ) were set for each plate. The level of DNA methylation was calculated according to the formula: $\left[1 /\left(1+2^{-\Delta \mathrm{Ct}}\right)\right] \times 100 \%$, where $\Delta C t=\mathrm{Ct}$ (unmethylated) $-\mathrm{Ct}$ (methylated) (23). Ct is the threshold of PCR cycle number at which the increase in fluorescent signal reaches a critical point. Each sample was analyzed in duplicate.

\section{Statistical Analysis}

The Student's $t$-test, Wilcoxon test and Chi-square test were used to analyze the differences in normal/near-normal characteristics, other continuous variables and categorical variables between participants in T2DM group and non-diabetic group. We then utilized linear regression model to exam the association between $E S R \alpha$ methylation level and lipid metabolism. Besides, the association between T2DM and lipid metabolism (as well as $E S R \alpha$ methylation level) were estimated using binary logistic regression model. The linear trends across increasing quartiles of $E S R \alpha$ methylation level and lipid metabolism were estimated by treating the median of each quartile as a continuous variable. The quartiles of ESR $\alpha$ methylation and lipid metabolism are shown in Supplementary Table 1. After stratifying the participants according to the median of ESR $\alpha$ promoter methylation level, we analyzed the interactive effect of $E S R \alpha$ methylation and lipid metabolism on the risk of T2DM by adding an interaction term "ESR $\alpha$ methylation * lipid metabolism" to the logistic regression model. In addition, we performed other interactive analyses by adding an interaction term ("ESR $\alpha$ methylation*gender" or "lipid metabolism*gender") to each models. According to the characteristics of the participants and the previous reports, we adjusted a variety of potential confounding variables (including age, gender, BMI, educational level, smoking, drinking and household income) in this study.

All statistical analyses were performed by SPSS 22.0 (IBM Corp, Armonk, NY, USA). The $P$-values $<0.05$ were considered statistically significant.

\section{RESULTS}

\section{Distribution of Variables in Different Groups}

The characteristics of the 1,143 residents are summarized in Table 1. As compared to the non-diabetic group, the T2DM group have a lower proportion of men/women, drinking and vegetables intake ( $\geq 500 \mathrm{~g} /$ day), and a higher proportion of illiteracy and family diabetes history $(P<0.05)$. Besides, the average age, BMI, TG and TC in T2DM group were higher than those in non-diabetic group $(P<0.05)$. The distributions of
TABLE 1 | Characteristics of participants in T2DM group and Nondiabetic group ${ }^{a}$.

\begin{tabular}{|c|c|c|c|c|}
\hline Characteristics & $\begin{array}{l}\text { T2DM group } \\
\qquad(n=237)\end{array}$ & $\begin{array}{c}\text { Nondiabetic } \\
\text { group } \\
(n=906)\end{array}$ & $t / \chi^{2} / Z$ & $P$ \\
\hline Age (years) & $57.58 \pm 8.96$ & $54.50 \pm 10.08$ & 4.588 & $<0.001$ \\
\hline Gender & & & 6.195 & 0.013 \\
\hline Men & $103(43.5)$ & $476(52.5)$ & & \\
\hline Women & $134(56.5)$ & $430(47.5)$ & & \\
\hline $\mathrm{BMI}\left(\mathrm{kg} / \mathrm{m}^{2}\right)$ & $26.35 \pm 3.70$ & $25.62 \pm 3.58$ & 2.785 & 0.005 \\
\hline Education level & & & 10.951 & 0.012 \\
\hline Illiteracy & $51(21.6)$ & $121(13.4)$ & & \\
\hline Primary school & $65(27.5)$ & $246(27.2)$ & & \\
\hline Junior high school & $93(39.4)$ & $406(44.9)$ & & \\
\hline High school and above & $27(11.4)$ & $131(14.5)$ & & \\
\hline Smoking & & & 1.875 & 0.171 \\
\hline Yes & 75 (31.6) & $330(36.4)$ & & \\
\hline No & $162(68.4)$ & $575(63.6)$ & & \\
\hline Drinking & & & 6.040 & 0.014 \\
\hline Yes & $34(14.3)$ & $195(21.5)$ & & \\
\hline No & $203(85.7)$ & $711(78.5)$ & & \\
\hline Vegetables intake (g/day) & & & 8.728 & 0.003 \\
\hline$\geq 500$ & $56(23.7)$ & $306(33.8)$ & & \\
\hline$<500$ & $180(76.3)$ & $600(66.2)$ & & \\
\hline Household income (RMB/year) & & & 0.826 & 0.662 \\
\hline$<6,000$ & $182(76.8)$ & $670(74.0)$ & & \\
\hline $6,000-12,000$ & $43(18.1)$ & $182(20.0)$ & & \\
\hline$>12,000$ & $12(5.1)$ & $54(6.0)$ & & \\
\hline Family diabetes history & & 5.869 & 0.015 & \\
\hline Yes & $52(22.2)$ & $140(15.6)$ & & \\
\hline No & $182(77.8)$ & $760(84.4)$ & & \\
\hline ESR $\alpha$ methylation (\%) & $4.58 \pm 2.22$ & $4.53 \pm 2.21$ & 0.338 & 0.735 \\
\hline $\mathrm{FPG}(\mathrm{mmol} / \mathrm{L})$ & $8.65(6.68,10.99)$ & $4.81(4.33,5.34)$ & 20.08 & $<0.001$ \\
\hline $\mathrm{TG}(\mathrm{mmol} / \mathrm{L})$ & $2.28 \pm 1.67$ & $1.72 \pm 1.29$ & 4.746 & $<0.001$ \\
\hline $\mathrm{TC}(\mathrm{mmol} / \mathrm{L})$ & $4.77 \pm 1.05$ & $4.58 \pm 0.97$ & 2.558 & 0.011 \\
\hline $\mathrm{HDL}-\mathrm{C}(\mathrm{mmol} / \mathrm{L})$ & $1.22 \pm 0.31$ & $1.24 \pm 0.30$ & 0.653 & 0.514 \\
\hline LDL-C (mmol/L) & $2.59 \pm 0.83$ & $2.59 \pm 0.75$ & 0.099 & 0.922 \\
\hline
\end{tabular}

RMB, China Yuan.

${ }^{a}$ Data are expressed as the mean $\pm S D$ or Median $(P 25, P 75)$ for continuous variables and $n(\%)$ for categorical variables.

household incomes, ESR $\alpha$ promoter methylation, HDL-C and LDL-C are comparable between the two groups.

After stratifying the participants according to the tertiles of age, we found that found that the levels of ESR $\alpha$ methylation, FPG and LDL-C in the elderly were elevated (all $P<0.05$ ). There is no statistically significant difference in the levels of TG, TC, HDL-C among different groups (Supplementary Table 2).

\section{Association Between ESR $\alpha$ Methylation Level and Lipid Metabolism}

As shown in Table 2, the HDL-C level showed a downward trend with the increase of the ESR $\alpha$ promoter methylation level regardless of gender stratification $(P$ for trend $<0.05)$. Besides, we found that in the continuous analysis, the ESR $\alpha$ promoter 
TABLE 2 | Association between ESR $\alpha$ methylation and lipid metabolism.

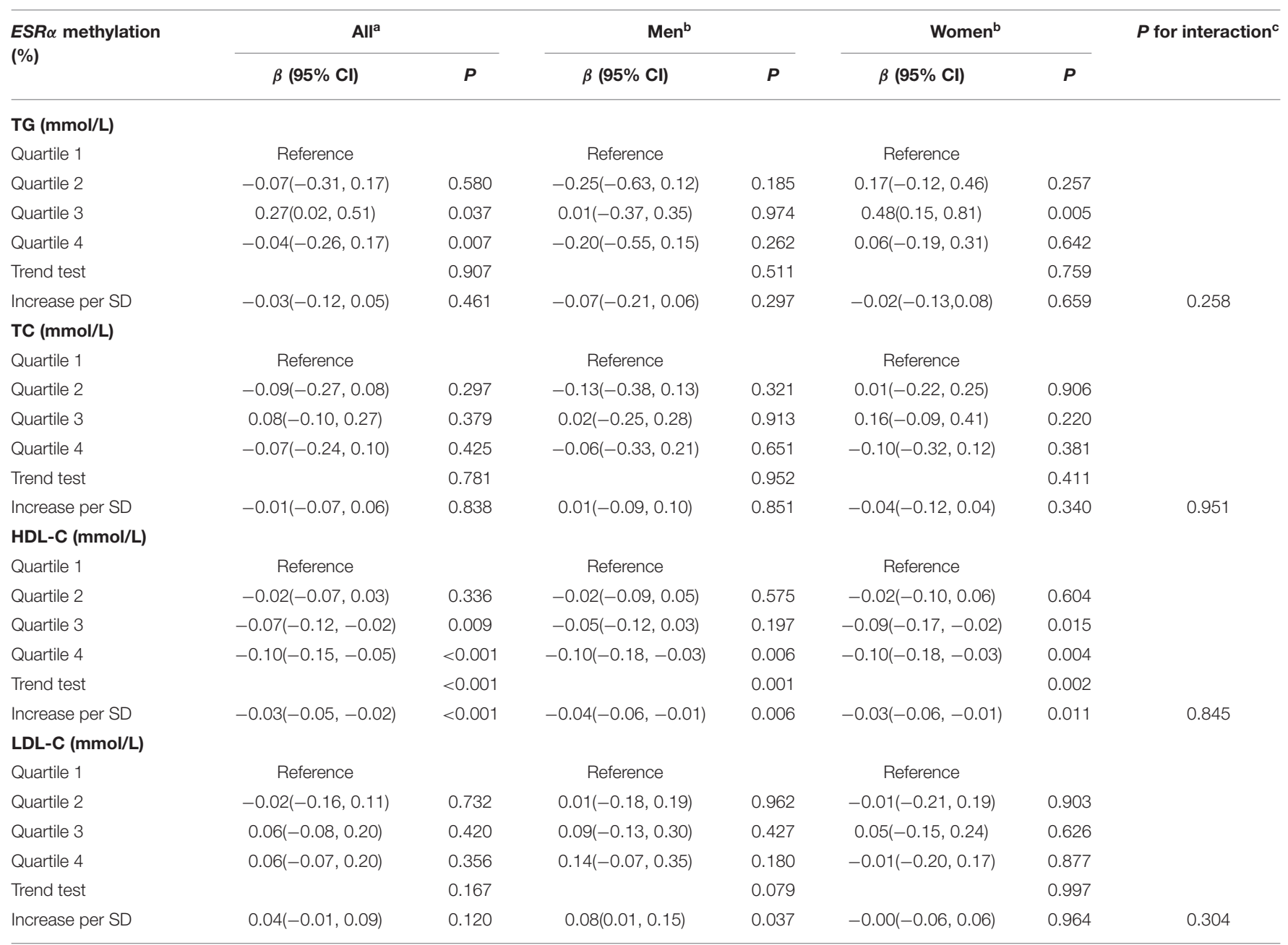

$S D$, standard deviation.

aAdjusted for age, gender, BMI, educational level, smoking, drinking, household income.

${ }^{b}$ Adjusted for age, BMI, educational level, smoking, drinking, household income.

${ }^{c}$ The interaction between ESR $\alpha$ methylation and gender.

methylation level was negatively associated with HDL-C levels whether gender stratification was performed (all $P<0.05$ ). For each unit standard deviation (SD) increment in ESR $\alpha$ promoter methylation, the level of HDL-C decreased by $0.03 \mathrm{mmol} / \mathrm{L}$ in all participants, $0.04 \mathrm{mmol} / \mathrm{L}$ in men and $0.03 \mathrm{mmol} / \mathrm{L}$ in women. Besides, we observed an increase of $0.08 \mathrm{mmol} / \mathrm{L}$ of LDL-C in men with each unit SD increment in ESR $\alpha$ promoter methylation level $(P=0.037)$.

\section{Association Between Lipid Metabolism and T2DM}

The association between lipid metabolism and T2DM is presented in Table 3. The risk of T2DM shown an upward trend with increasing quartiles of TG whether gender stratification was performed (all $P$ for trend $<0.05$ ). In continuous analysis, after adjusting for potential confounding factors, each unit SD increase in TG was associated with an increase of $43 \%, 36 \%$ and $49 \%$ in the risk of T2DM in all population, men and women respectively (all $P<0.05$ ).

In addition, the risk of T2DM shown a downward trend with increasing levels of HDL-C in men ( $P$ for trend $<0.05$ ). In continuous analysis, we observed a decrement of $25 \%$ in the risk of T2DM with each unit SD increase of HDL-C levels in men. Furthermore, the interactive effect between HDL-C and gender on the risk of T2DM was evaluated, and significant association was observed.

\section{The Role of ESR $\alpha$ Methylation in the Association Between Lipid Metabolism and T2DM}

We did not find any association between ESR $\alpha$ promoter methylation and FPG (Supplementary Table 3) or T2DM (Table 4). After stratifying the population into two groups by the ESR $\alpha$ promoter methylation level, we found that the risk 
TABLE 3 | Association between lipid metabolism and T2DM.

\begin{tabular}{|c|c|c|c|c|c|c|c|}
\hline \multirow{2}{*}{$\begin{array}{l}\text { Lipid metabolism } \\
\text { (mmol/L) }\end{array}$} & \multicolumn{7}{|c|}{ T2DM } \\
\hline & OR $(95 \% \mathrm{Cl})$ & $P$ & OR $(95 \% \mathrm{Cl})$ & $P$ & OR $(95 \% \mathrm{Cl})$ & $P$ & $P$ for interaction ${ }^{c}$ \\
\hline \multicolumn{8}{|l|}{ TG } \\
\hline Quartile 1 & Reference & & Reference & & Reference & & \\
\hline Quartile 4 & $2.30(1.59,3.33)$ & $<0.001$ & $2.64(1.49,4.65)$ & 0.001 & $1.91(1.16,3.14)$ & 0.011 & \\
\hline Trend test & & $<0.001$ & & $<0.001$ & & 0.011 & \\
\hline Increase per SD & $1.43(1.25,1.64)$ & $<0.001$ & $1.36(1.13,1.64)$ & 0.001 & $1.49(1.21,1.83)$ & $<0.001$ & 0.549 \\
\hline \multicolumn{8}{|l|}{ TC } \\
\hline Quartile 1 & Reference & & Reference & & Reference & & \\
\hline Increase per SD & $1.15(0.99,1.33)$ & 0.061 & $1.03(0.84,1.29)$ & 0.722 & $1.18(0.96,1.45)$ & 0.121 & 0.426 \\
\hline \multicolumn{8}{|l|}{ HDL-C } \\
\hline Quartile 1 & Reference & & Reference & & Reference & & \\
\hline Quartile 2 & $0.90(0.60,1.34)$ & 0.593 & $0.82(0.46,1.45)$ & 0.489 & $0.98(0.54,1.77)$ & 0.941 & \\
\hline Quartile 3 & $0.81(0.54,1.24)$ & 0.331 & $0.66(0.35,1.22)$ & 0.184 & $0.99(0.54,1.81)$ & 0.977 & \\
\hline Quartile 4 & $0.91(0.59,1.41)$ & 0.679 & $0.47(0.22,0.97)$ & 0.041 & $1.55(0.86,2.81)$ & 0.148 & \\
\hline Trend test & & 0.478 & & 0.010 & & 0.168 & \\
\hline Increase per SD & $0.99(0.85,1.15)$ & 0.862 & $0.75(0.58,0.97)$ & 0.028 & $1.18(0.97,1.44)$ & 0.097 & 0.019 \\
\hline \multicolumn{8}{|l|}{ LDL-C } \\
\hline Quartile 1 & Reference & & Reference & & Reference & & \\
\hline
\end{tabular}

$S D$, standard deviation.

aAdjusted for age, gender, BMI, educational level, smoking, drinking, household income.

${ }^{b}$ Adjusted for age, BMI, educational level, smoking, drinking, household income.

${ }^{c}$ The interaction between lipid metabolism and gender.

of $\mathrm{T} 2 \mathrm{DM}$ in participants with lower methylation $(\leq 4.07 \%)$ were more susceptible to HDL-C ( $P$ for interaction $=0.030)$, as manifested by a decreased of $22 \%$ in the risk of T2DM with the increment of each unit SD in HDL-C concentration (Table 5).

\section{DISCUSSION}

In the current study, we explored the demographic information of the demographic information and found that the prevalence of T2DM in men is significantly lower than in women. Several previous studies have also observed gender differences in the prevalence of T2DM (24-26). Among them, a large-scale epidemiological survey found that the risk of T2DM in male farmers in rural areas is lower than in female farmers (26). The physical activity has been reported to mitigate the impaired glucose tolerance caused by unhealthy lifestyle (such as sleep loss) (27) and prevent the occurrence of T2DM (28). Farmers were recruited as participants in our study. And the level of physical activity of male farmers is significantly higher than that of female farmers (29), which may lead to a lower prevalence of T2DM in men.

Besides, the association between $E S R \alpha$ promoter methylation and lipid metabolism was investigated. And negative correlations were observed between ESR $\alpha$ promoter methylation and HDL-C levels, whether gender stratification was performed. Considering that the ESR $\alpha$ promoter methylation can suppress the protein expression of ESR $\alpha$ (30), we speculate that the ESR $\alpha$ levels may relate positively to the HDL-C levels in adults. These findings are similar to the previous studies $(12,31)$. The expression of LDL receptor has been reported to depend on tyrosine kinase and protein kinase $\mathrm{C}$ activation, both signal pathways could be activated by estrogen (32). Additionally, as a regulator of LDL-C metabolism, ESR $\alpha$ can affect the gene expression of LDL-C receptors (33). Whereas Knopp et al. (34) observed a lesser change in low-density lipoprotein in women than men with high-carbohydrate or high-fat feeding. Here, we only observed 
TABLE 4 | Association between ESR $\alpha$ methylation and T2DM.

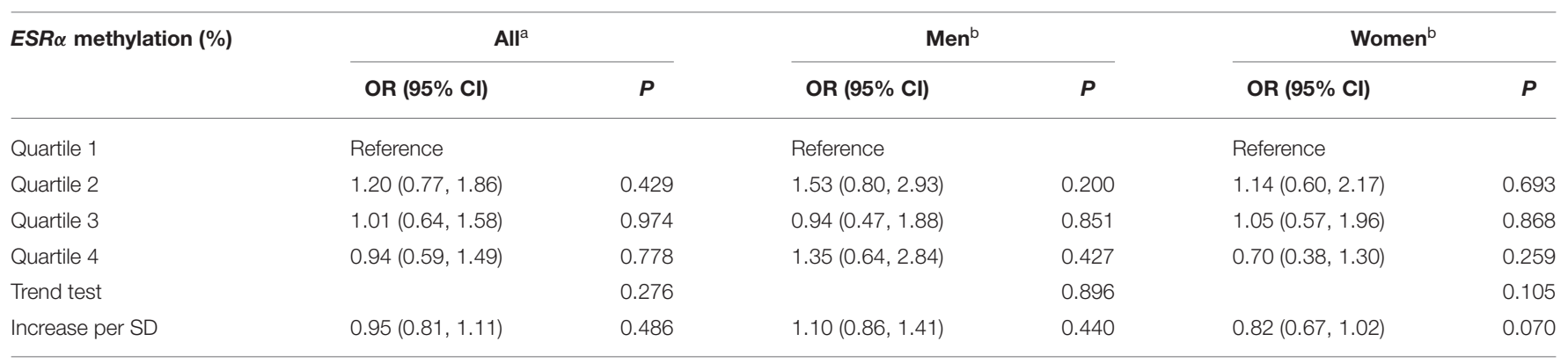

$S D$, standard deviation.

a Adjusted for age, gender, BMI, educational level, smoking, drinking, household income.

${ }^{b}$ Adjusted for age, BMI, educational level, smoking, drinking, household income.

TABLE 5 | Interactive effects of ESR $\alpha$ methylation and lipid metabolism indexes on T2DM.

\begin{tabular}{|c|c|c|c|c|}
\hline Lipid metabolism & Groups & \multicolumn{3}{|c|}{ T2DM $^{\mathrm{a}}$} \\
\hline \multirow{2}{*}{ TG } & $\leq 4.07 \%$ & $1.34(1.08,1.65)$ & 0.007 & \\
\hline & $>4.07 \%$ & $1.67(1.34,2.09)$ & $<0.001$ & \\
\hline \multirow[t]{2}{*}{ TC } & ESR $\alpha$ methylation & & & 0.757 \\
\hline & $>4.07 \%$ & $1.22(0.98,1.53)$ & 0.082 & \\
\hline \multirow[t]{3}{*}{ HDL-C } & $E S R \alpha$ methylation & & & 0.030 \\
\hline & $\leq 4.07 \%$ & $0.78(0.61,1.00)$ & 0.046 & \\
\hline & $>4.07 \%$ & $1.04(0.83,1.31)$ & 0.736 & \\
\hline LDL-C & $E S R \alpha$ methylation & & & 0.273 \\
\hline
\end{tabular}

${ }^{a}$ Adjusted for age, gender, BMI, educational level, smoking, drinking, household income.

${ }^{b}$ The interaction between lipid metabolism and ESR $\alpha$ methylation.

a positive correlation between $E S R \alpha$ promoter methylation and LDL-C levels in men, whereas no association was observed in women, further suggesting that LDL-C may be affected by genetic factors in a gender-specific manner.

The concentrations of LDL-C in patients with T2DM are generally not significantly different from those in non-diabetic patients (35). Similarly, no significant association between the levels of LDL-C and the risk of T2DM was observed in the present study. This may be caused by the the management of LDL-C or the reduction of LDL-C catabolism in patients $(8,36)$. Besides, we here found that the risk of T2DM was positively associated with TG whether gender stratification was performed. Besides, we observed a negative correlation between HDL-C levels and the risk of T2DM in men, instead of women. As revealed in the previous study (37), the dominant lipid abnormality in diabetes is hypertriglyceridemia, which is commonly associated with a reduction in HDL-C. Our findings are similar to the previous study, suggesting that TG and HDL-C may be closely related to the risk of T2DM. Hanai et al. (38) found that the levels of HDL$\mathrm{C}$ were associated with the progression of diabetic kidney disease in men but not in women. In addition, a greater difference in those with diabetes compared with those without diabetes were observed in women than in men for HDL-C (39). Combining these findings, we speculate that there may be gender difference in relationship between HDL-C and T2DM, and a relatively small alteration in HDL-C may trigger the occurrence of T2DM in male.

A previous study found that the level of ESR $\alpha$ promoter methylation in decidual tissue of Germans with gestational diabetes mellitus (GDM) is higher than that of Germans without GDM (40), indicating that $E S R \alpha$ promoter methylation may increase the risk of GDM. While in this study, we did not observe any association between ESR $\alpha$ promoter methylation and FPG or the risk of T2DM. These inconsistencies may be due to the obvious difference races and different types of diabetes mellitus. Notably, many reproducible studies found that the polymorphisms in the same site (rs1801282 in PPARG gene) is not significantly associated with the risk of GDM, while it can elevate the risk of T2DM (41), suggesting that the same genetic changes may have different associations 
with different types of diabetes mellitus $(42,43)$. Finally, we observed a significant interactive effect of ESR $\alpha$ promoter methylation and HDL-C on the risk of T2DM, indicating that the level of ESR $\alpha$ methylation may modify the association between HDL-C and the risk of T2DM, and the risk of $\mathrm{T} 2 \mathrm{DM}$ in participants with lower $E S R \alpha$ methylation is more susceptible to the alteration of HDL-C. Different DNA fragments located in the same gene may have different methylation levels and thus result in different biological effects (44). Consequently, further comprehensive methylation sequencing in large population may provide more clues for the pathogenesis of T2DM.

\section{CONCLUSION}

In summary, lipid metabolism was associated with the levels of ESR $\alpha$ promoter methylation and the risks of T2DM. Additionally, ESR $\alpha$ promoter methylation can modify the association of HDL-C and T2DM.

\section{DATA AVAILABILITY STATEMENT}

The raw data supporting the conclusions of this article will be made available by the authors, without undue reservation.

\section{ETHICS STATEMENT}

The studies involving human participants were reviewed and approved by The project was approved by the

\section{REFERENCES}

1. Wang Z, Sun J, Han R, Fan D, Dong X, Luan, Z, et al. Efficacy and safety of sodium-glucose cotransporter-2 inhibitors versus dipeptidyl peptidase- 4 inhibitors as monotherapy or add-on to metformin in patients with type 2 diabetes mellitus: A systematic review and meta-analysis. Diabetes, Obes Metab. (2018) 20:113-20. doi: 10.1111/dom.13047

2. Zhang X, Liu J, Jin K, Xu H, Wang C, Zhang, Z. et al. Subcutaneous injection of hydrogen gas is a novel effective treatment for type 2 diabetes. J Diabetes Investig. (2018) 9:83-90. doi: 10.1111/jdi.12674

3. Vijayakumar G, Manghat S, Vijayakumar R, Simon L, Scaria LM, Vijayakumar, A, et al. Incidence of type 2 diabetes mellitus and prediabetes in Kerala, India: results from a 10-year prospective cohort. BMC Public Health. (2019) 19:140. doi: 10.1186/s12889-019-6445-6

4. Yan L, Xu MT, Yuan L, Chen B, Xu ZR, Guo, QH, et al. Prevalence of dyslipidemia and its control in type 2 diabetes: A multicenter study in endocrinology clinics of China. J Clin Lipidol. (2016) 10:150-60. doi: $10.1016 /$ j.jacl.2015.10.009

5. Verges, B. Pathophysiology of diabetic dyslipidaemia: where are we? Diabetologia. (2015) 58:886-99. doi: 10.1007/s00125-015-3525-8

6. Petersen KF, Dufour S, Savage DB, Bilz S, Solomon G, Yonemitsu S, et al. The role of skeletal muscle insulin resistance in the pathogenesis of the metabolic syndrome. Proc Natl Acad Sci USA. (2007) 104:12587-94. doi: 10.1073/pnas.0705408104

7. Opoku S, Gan Y, Fu W, Chen D, Addo-Yobo E, Trofimovitch D, et al. Prevalence and risk factors for dyslipidemia among adults in rural and urban China: findings from the China National Stroke
Institutional Review Board of Zhengzhou University. The patients/participants provided their written informed consent to participate in this study.

\section{AUTHOR CONTRIBUTIONS}

LW, HH, WL, CW, and YB designed the research. GZ, XL, RS, and ZL collected the data. RS and LL performed the experiments. GZ and LL analyzed the data and wrote the manuscript. YB revised the language/article. All authors read and approved the final manuscript.

\section{FUNDING}

This study was supported by the National Natural Science Foundation of China (81972981 and 81673116) and Key Projects of Colleges and Universities of Henan Education Department (21A330006). The sponsors were not involved in research design, information collection, data analysis, or paper writing.

\section{ACKNOWLEDGMENTS}

We are sincerely grateful to all participants for their contribution.

\section{SUPPLEMENTARY MATERIAL}

The Supplementary Material for this article can be found online at: https://www.frontiersin.org/articles/10.3389/fpubh. 2021.578134/full\#supplementary-material
Screening and prevention project (CNSSPP). BMC Public Health. (2019) 19:1500. doi: 10.1186/s12889-019-7827-5

8. Scicali R, Di Pino A, Ferrara V, Urbano F, Piro S, Rabuazzo AM, et al. New treatment options for lipid-lowering therapy in subjects with type 2 diabetes. Acta Diabetologica. (2018) 55:209-18. doi: 10.1007/s00592-017-1089-4

9. Khor VK, Dhir R, Yin X, Ahima RS, Song WC. Estrogen sulfotransferase regulates body fat and glucose homeostasis in female mice. Am J Physiol Endocrinol Metab. (2010) 299:E657-64. doi: 10.1152/ajpendo.00707.2009

10. Vogel H, Mirhashemi F, Liehl B, Taugner F, Kluth O, Kluge R, et al. Estrogen deficiency aggravates insulin resistance and induces $\beta$-cell loss and diabetes in female New Zealand obese mice. Horm Metab Res. (2013) 45:430-5. doi: $10.1055 / \mathrm{s}-0032-1331700$

11. Gupte AA, Pownall HJ, Hamilton DJ. Estrogen: an emerging regulator of insulin action and mitochondrial function. J Diabetes Res. (2015) 2015:916585. doi: 10.1155/2015/916585

12. Khristi V, Ratri A, Ghosh S, Pathak D, Borosha S, Dai E, et al. Disruption of ESR1 alters the expression of genes regulating hepatic lipid and carbohydrate metabolism in male rats. Mol Cell Endocrinol. (2019) 490:4756. doi: 10.1016/j.mce.2019.04.005

13. Mauvais-Jarvis F, Manson JE, Stevenson JC, Fonseca VA. Menopausal hormone therapy and type 2 diabetes prevention: evidence, mechanisms, and clinical implications. Endocr Rev. (2015) 38:173-88. doi: 10.1210/er.2016-1146

14. Mauvais-Jarvis F. Menopause, estrogens, and glucose homeostasis in women. Adv Exp Med Biol. (2017) 1043:217-25. doi: 10.1007/978-3-319-70178-3_11

15. Meyer MR, Clegg DJ, Prossnitz ER, Barton, M. Obesity, insulin resistance and diabetes: sex differences and role of oestrogen receptors. Acta Physiologica. (2011) 203:259-69. doi: 10.1111/j.1748-1716.2010.02237.x 
16. Ribas V, Nguyen MT, Henstridge DC, Nguyen AK, Beaven SW, Watt MJ, et al. Impaired oxidative metabolism and inflammation are associated with insulin resistance in ERalpha-deficient mice. Am J Physiol Endocrinol Metab. (2010) 298:E304-19. doi: 10.1152/ajpendo.00504.2009

17. Maekawa R, Mihara Y, Sato S, Okada M, Tamura I, Shinagawa M, et al. Aberrant DNA methylation suppresses expression of estrogen receptor 1 (ESR1) in ovarian endometrioma. J Ovarian Res. (2019) 12:14. doi: 10.1186/s13048-019-0489-1

18. Yang BT, Dayeh TA, Kirkpatrick CL, Taneera J, Kumar R, Groop L, et al. Insulin promoter DNA methylation correlates negatively with insulin gene expression and positively with $\mathrm{HbA}(1 \mathrm{c})$ levels in human pancreatic islets. Diabetologia. (2011) 54:360-7. doi: 10.1007/s00125-010-1967-6

19. Papikian A, Liu W, Gallego-Bartolomé J, Jacobsen SE. Site-specific manipulation of Arabidopsis loci using CRISPR-Cas9 SunTag systems. Nat Commun. (2019) 10:729. doi: 10.1038/s41467-019-08736-7

20. Alberti KG, Zimmet PZ. Definition, diagnosis and classification of diabetes mellitus and its complications. Part 1: diagnosis and classification of diabetes mellitus provisional report of a WHO consultation. Diabetic Med. (1998) 15:53953. doi: 10.1002/(sici)1096-9136(199807)15:7<539::aid-dia668>3.0.co;2-s

21. Barham D, Trinder P. An improved colour reagent for the determination of blood glucose by the oxidase system. Analyst. (1972) 97:142-5. doi: 10.1039/an9729700142

22. Yu Z, Armant O, Fischer R. Fungi use the SakA (HogA) pathway for phytochrome-dependent light signalling. Nat Microbiol. (2016) 1:16019. doi: 10.1038/nmicrobiol.2016.19

23. Lu L, Katsaros D, Rigault de la Longrais IA, Sochirca O, Yu H. Hypermethylation of let-7a-3 in epithelial ovarian cancer is associated with low insulin-like growth factor-II expression and favorable prognosis. Cancer Res. (2007) 67:10117-22. doi: 10.1158/0008-5472.can-07-2544

24. Choi SE, Liu M, Palaniappan LP, Wang EJ, Wong ND. Gender and ethnic differences in the prevalence of type 2 diabetes among Asian subgroups in California. J Diabetes Complications. (2013) 27:429-35. doi: 10.1016/j.jdiacomp.2013.01.002

25. Chang H-Y, Hsu C-C, Pan W-H, Liu W-L, Cheng JY-C, Tseng C$\mathrm{H}$, et al. Gender differences in trends in diabetes prevalence from 1993 to 2008 in Taiwan. Diabetes Res Clin Pract. (2010) 90:358-64. doi: 10.1016/j.diabres.2010.09.032

26. Liu X, Mao Z, Li Y, Wu W, Zhang X, Huo W, et al. Cohort profile: the henan rural cohort: a prospective study of chronic non-communicable diseases. Int $J$ Epidemiol. (2019) 48:1756. doi: 10.1093/ije/dyz039

27. Saner NJ, Lee MJC, Kuang J, Pitchford NW, Roach GD, Garnham A, et al. Exercise mitigates sleep loss-induced changes in glucose tolerance, mitochondrial function, sarcoplasmic protein synthesis, and diurnal rhythms. Mol Metab. (2020) 43:101110. doi: 10.1016/j.molmet.2020.101110

28. Baik I, Park SI. Associations of alcohol consumption and physical activity with lean type 2 diabetes mellitus among Korean adults: a prospective cohort study. PLoS ONE. (2020) 15:e0238641. doi: 10.1371/journal.pone.0238641

29. Maruyama S, Nakamura, S. Why are women slimmer than men in developed countries? Econ Hum Biol. (2018) 30:1-13. doi: 10.1016/j.ehb.2018. 04.002

30. Tsuboi K, Nagatomo T, Gohno T, Higuchi T, Sasaki S, Fujiki N, et al. Single CpG site methylation controls estrogen receptor gene transcription and correlates with hormone therapy resistance. J Steroid Biochem Mol Biol. (2017) 171:209-17. doi: 10.1016/j.jsbmb.2017.04.001

31. Pynadath TI, Chanapai S. Elevation of serum HDL and HDL cholesterol in cholesterol in cholesterol-FED male rabbits treated with estrogen. Atherosclerosis. (1981) 38:255-65.

32. Distefano E, Marino M, Gillette JA, Hanstein B, Pallottini V, Brüning J, et al. Role of tyrosine kinase signaling in estrogen-induced LDL receptor gene expression in HepG2 cells. Biochim Biophys Acta. (2002) 1580:145-9. doi: 10.1016/s1388-1981(01)00197-4

33. Brüning JC, Lingohr $\mathrm{P}$, Gillette J, Hanstein B, Avci H, Krone W, et al. Estrogen receptor- $\alpha$ and Sp1 interact in the induction of the low density lipoprotein-receptor. J Steroid Biochem Mol Biol. (2003) 86:11321. doi: 10.1016/s0960-0760(03)00263-2

34. Knopp RH, Paramsothy P, Retzlaff BM, Fish B, Walden C, Dowdy A, et al. Gender differences in lipoprotein metabolism and dietary response: Basis in hormonal differences and implications for cardiovascular disease. Curr Atheroscler Rep. (2005) 7:472-9. doi: 10.1007/s11883-005-0065-6

35. Krentz AJ. Lipoprotein abnormalities and their consequences for patients with Type 2 diabetes. Diabetes Obes Metab. (2003)5:S19-27. doi: 10.1046/j.1462-8902.2003.0310.x

36. Verges B. Lipid modification in type 2 diabetes: the role of LDL and HDL. Fundam Clin Pharmacol. (2009) 23:6815. doi: $10.1111 / j .1472-8206.2009 .00739 . x$

37. Quispe R, Martin SS, Jones SR. Triglycerides to high-density lipoproteincholesterol ratio, glycemic control and cardiovascular risk in obese patients with type 2 diabetes. Curr Opin Endocrinol Diabetes Obes. (2016) 23:150-6. doi: 10.1097/MED.0000000000000241

38. Hanai K, Babazono T, Yoshida N, Nyumura I, Toya K, Hayashi T, et al. Gender differences in the association between HDL cholesterol and the progression of diabetic kidney disease in type 2 diabetic patients. Nephrol Dial Transplantation. (2012) 27:1070-5. doi: 10.1093/ndt/gfr417

39. Howard BV, Cowan LD, Go O, Welty TK, Robbins DC, Lee ET. Adverse effects of diabetes on multiple cardiovascular disease risk factors in women. Strong heart study. Diabetes Care. (1998) 21:1258-65. doi: 10.2337/diacare.21.8.1258

40. Knabl J, Hiden U, Hüttenbrenner R, Riedel C, Hutter S, Kirn V, et al. GDM alters expression of placental estrogen receptor $\alpha$ in a cell type and gender-specific manner. Reprod Sci. (2015) 22:148895. doi: 10.1177/1933719115585147

41. Mao H, Li Q, Gao S. Meta-analysis of the relationship between common type 2 diabetes risk gene variants with gestational diabetes mellitus. PLOS ONE. (2012) 7:e45882. doi: 10.1371/journal.pone.0045882

42. Anna M, Lluis G, Jose-Manuel FR, Joan V, Inmaculada S, Cristina G, et al. Mannose-binding lectin gene polymorphisms are associated with gestational diabetes mellitus. J Clin Endocrinol Metab. (2004) 89:5081-7. doi: $10.1210 / j c .2004-0211$

43. Gu HF. Genetic variation screening and association studies of the adenylate cyclase activating polypeptide 1 (ADCYAP1) gene in patients with type 2 diabetes. Hum Mutat. (2010) 19:572-6. doi: 10.1002/humu.9034

44. Fabrizio FP, Sparaneo A, Centra F, Trombetta D, Storlazzi CT, Graziano P, et al. Methylation density pattern of KEAP1 gene in lung cancer cell lines detected by quantitative methylation specific PCR and pyrosequencing. Int J Mol Sci. (2019) 20:E2697. doi: 10.3390/ijms20112697

Conflict of Interest: The authors declare that the research was conducted in the absence of any commercial or financial relationships that could be construed as a potential conflict of interest.

The reviewer DH declared a shared affiliation, with no collaboration, with the authors to the handling editor at the time of the review.

Copyright $\odot 2021$ Zhou, Liu, Li, Hou, Wang, Sun, Huang, Li, Li, Wang and Ba. This is an open-access article distributed under the terms of the Creative Commons Attribution License (CC BY). The use, distribution or reproduction in other forums is permitted, provided the original author(s) and the copyright owner(s) are credited and that the original publication in this journal is cited, in accordance with accepted academic practice. No use, distribution or reproduction is permitted which does not comply with these terms. 